\title{
Shipboard Waste Incineration Online Accuracy Monitoring
}

\author{
Chen xin'en ${ }^{1, a}$, Guo shijun ${ }^{2, b}$ and Qing haofeng ${ }^{3, c}$ \\ ${ }^{1}$ Hongshan three road 101 , huangpu district, guangzhou,china \\ ${ }^{2}$ Hongshan three road 101 , huangpu district, guangzhou,china \\ ${ }^{3}$ Hongshan three road 101, huangpu district ,guangzhou,china
}

Key words: shipboard incinerator, monitoring and control system, PLC, remote monitoring Abstract: Focused on uneasy monitoring of shipboard incineration, we employ the latest achievements of automation and information technology as well as PLC to successfully realize intelligent and ship-shore monitoring. In terms of combustion monitoring, various system parameters are under strict and real-time monitoring, and operation data on shipboard incinerator would then be transmitted to the shore through Internet, which can realize remote monitoring and control of environmental protection equipment. It is a new model to protect marine environment. This burning and monitoring system is of high reliability, excellent function and advanced technology, enjoying broad market prospects.

\section{Introduction}

Nowadays global environment protection has put forward higher standards for monitoring and preventing pollution from ships. According to the International Convention MARPOL73/78[1-3], shipboard incinerator is one of the necessary anti-pollution equipment on ocean-going vessels. Many countries have developed a variety of shipboard incinerators, most of which are equipped with auxiliary burner and possess several advantages such as high degree of automation and the capacity to burn sludge oil and solid waste. To monitor important parameters related to environmental protection and avoid crew's violation of relevant laws and regulations, the management and operation of shipboard incinerators also need to be optimized. Against such a background, we put forward an auto-combustion system and corresponding detection methods based on PLC and satellite communication technologies so as to realize the monitoring. We have offered new solutions to ship-shore real-time monitoring, ensuring that shipboard waste incineration meets environmental protection requirements.

\section{Combustion Control Based on PLC}

Shipboard incinerator system mainly consists of a shipboard furnace, waste oil system, diesel engines, compressed air system, air supply system and electrical control system [4]. The furnace is mainly composed of diesel oil burner, waste oil burner, ignition electrode, combustion chamber, clean-out door and feeding door, taking the work of garbage or waste oil burning.

\section{Design Requirements}

The control system shall achieve perfect program control, combustion control and security [5].

(1) Program Control

Through predesigned program, the control system of shipboard incinerator shall automatically control the operation shipboard incinerator such as pre scavenging, fuel injection, ignition, combustion, stalling and after scavenging. 


\section{(2) Combustion Control}

The control system of shipboard incinerator shall automatically control fuel injection quantity, air damper opening and temperature of combustion chamber, ensuring that maximum amount of solid waste or waste oil can be burned with minimum consumption of diesel.

(3) Safety Requirements

Shipboard incinerator shall automatically shutdown, stop fuel supply and give sound and light alarm under the following situations: low voltage or power failure occurs, flue gas temperature reaches higher than $350^{\circ} \mathrm{C}$, combustion chamber temperature rises to $1200^{\circ} \mathrm{C}$ and above, pressure in combustion chamber is coming to the level of atmospheric pressure, ignition failure or flame failure happens and low fuel pressure occurs.

\section{Hardware Design of the Control System}

Control system is the core of shipboard incinerator system, representing the intelligence level of shipboard incinerator. Most of the control equipments are installed in electrical control box. The control box mainly houses the following equipments: operation switch, display control panel and indicator switch on the front; disconnect switch, relay, AC contactor, transformer, PLC (Programmable Logic Control) in the box. Among these equipments, PLC is the core component of control system. We choose CPU226 (Central Processing Unit 226) PLC of S7-200 series because it has advantages of low cost and good functions, and its 24 inputs and 16 output points can meet the requirements of the control system for shipboard incinerator[6]. EM235 expansion module is selected because it has 4 inputs and 1 output which can convert the external analog signals into digital signals and then transmit them into the PLC. Finally, the extension module would convert the digital signals from the PLC into analog signals in order to control the controlled object.

Arrangement of CPU226 PLC (in S7-200 series) input and output ports is shown in Table 1. Primary-terminal control equipment is installed in the body of incinerator, mainly including thermocouple, RTD, sensor, pressure sensors, and fire detectors. Display Control Screen is usually used to display and adjust incinerator parameters and allows staff to operate the incinerator easily. 400C Text Display is chosen as the Display Control Screen because it is cheap and convenient, providing special support for S7-200. TD 400C is connected with S7-200CPU by TD/CPU cable [7].

\section{Design of Shipboard Monitoring and Control System}

\section{Feature Requirement}

(1) Monitor and display real-time performance of incinerator. The monitoring and control system shall be able to collect and display operational parameters of all devices.

(2) Control the operation of equipment in shipboard incineration system. The monitoring and control system shall be able to start or stop all operating devices in the incineration system.

(3) Set and modify operational parameters of the shipboard incineration system. The monitoring and control system shall be able to modify operational parameters according to actual operating status to ensure the shipboard incinerators in best working condition.

(4) Monitor and handle system failures. The monitoring and control system shall give out audio and visual alarms when parameters reached alarm status so as to ensure that the system operates safe and sound.

\section{Hardware Design}

Hardware design of the monitoring and control system for shipboard waste incineration is shown in figure 1. The hardware mainly consists of PLC controller, human-computer interaction (HCI) module, video capture module, flame detector, flow sensor, and weight sensor. Human-computer 
interaction (HCI) module, flame detector, flow sensor, and weight sensor are connected to PLC controller respectively, while human-computer interaction (HCI) module is also connected to video capture module.

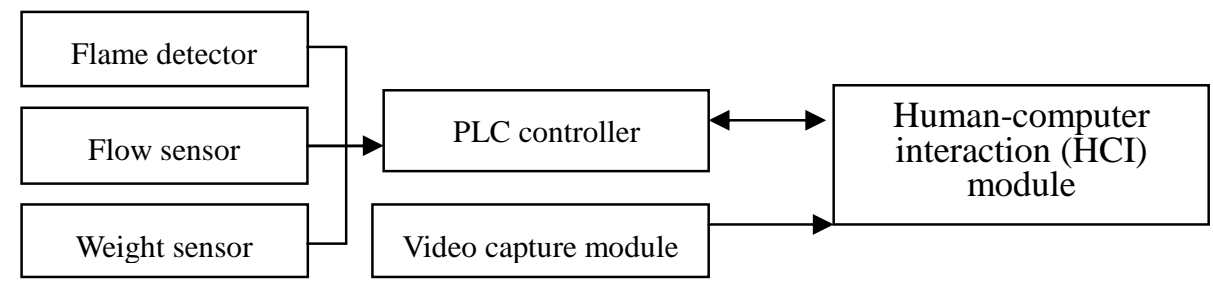

Figure 1 Monitoring and Control System for Shipboard Waste Incineration

\section{Software Design}

The software design is divided into design of PLC working procedure software and design of touch screen interface. Since shipboard incinerators have different working patterns, PLC working procedure shall be designed for three incineration models, namely, solid waste incineration model, sludge oil incineration model, and sludge oil and solid waste incineration model. MCGS (Monitor and Control Generated System) embedded configuration software is targeted at touch screen and can realize the function of data collection and monitor as well as front-end data process and control.

\section{Design of Shore-Based Application System}

\section{Ship-Shore-Integrated Monitoring System}

The Ship-shore-integrated Monitoring System consists of three parts, namely, the Ship Monitoring and Control System, the Ship-Shore Communication System and the Shore-based Application System. Its principles are shown in figure 4. Data collected by different sensors installed in the ship monitoring and control system are encrypted and compressed by data transmission control module before being sent to the Beidou Satellite Ground Station through Beidou Navigation System. Finally the data reach to the Beidou Operation Service Center. After being spotted by the center's timely scan and analysis, new data will be saved in a database and sent to onshore application terminals and then visited by professionals from maritime administrative departments and ship management companies [14]. The center can refer to relevant data and information from Shore-based Application System to realize real-time and accurate monitoring of shipboard incinerators. It can also judge whether the crew dump waste and sludge oil into the sea through calculating and analyzing relevant data. In this way, the efficiency of supervision against marine pollution will be improved. 


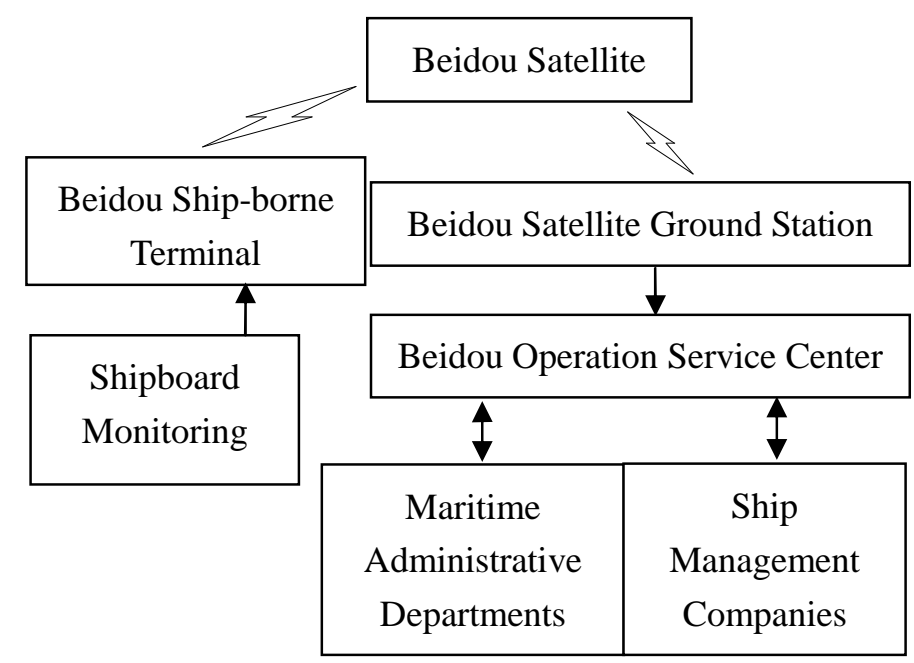

Figure 4 Schematic Diagram of Ship-Shore-Integrated Monitoring System

Based on Visual Studio 2008, the Shore-based Application System is a type of remote information management system[15] that aims to improve the efficiency of and the information technology application in the supervision of shipboard incinerators. This system is mainly targeted at maritime administrative departments and ship management companies.

The main interface of onshore application terminals consists of eight submenus, namely, Shipboard Information Check, Real-Time Monitoring, Operation Time Check, Sludge Oil Handling Capacity Check, Solid Waste Handling Capacity Check, Real-time Video Monitoring Check, Alert Control and Ship-Shore Information Handling. The monitoring and control system can realize the exchange of information between ship and shore and also display, save and search information sent by onshore maritime administrative departments and ship management companies.

\section{Conclusions}

The real-time monitoring and management of shipboard incinerators plays a critical role in ocean environmental protection. This system can display different parameters concerning the operation of shipboard incinerators and carry out remote monitoring of significant parameters in terms of maritime environmental protection via Internet on shore. Besides, it also adopts real-time data collecting techniques and remote monitoring techniques. Thus it is safe to conclude that the system put forward in this paper innovates maritime environmental protection. What's more, its powerful interface has improved the reliability and convenience in managing and monitoring shipboard waste incineration. Real-time monitoring of shipboard incineration system goes through the whole incineration process, making monitoring work safer, more reliable and convenient, which has great significance to the development of shipboard waste handling technology as well as maritime environmental protection.

\section{References:}

[1] Wang, J.Q., \& Chen, J.S. (2010). On the Treatment Technology of Ships Pollutants and Its Development Trend. Ship \& Ocean Engineering, (6): 71-77.

[2] Cui, J.W., Han, X.B., \&Xu, X.X. (2010). Three-dimensional Numerical Simulation of the Integral Structure of Marine Garbage Incinerator. Ship \& Ocean Engineering, (2): 143-146. 
[3] Men.Z.R., \&Wang. C.M. (2012). New Technique Development of Marine Incinerator. Transportation Science \& Technology, (1): 104-106.

[4] Standardization Administration of the People's Republic of China. (2008). GB/T 10836 - 2008: Requirements of Shipboard Incinerators. Beijing: China Standardization Press.

[5] Yin, P.H. (2000). Ship Pollution Prevention Technology. Dalian: Dalian Maritime University Press, $136-143$.

[6] Tian, S.Z. (2009). S7-200 PLC Principles \& Application. Beijing: China Machine Press, $11 \sim 13$.

[7] Liao, C.C. (2008). PLC Programming \& Application. Beijing: China Machine Press, 246 248.

[8] Liu, C.G. (2014). Design and Realization of Remote Monitoring System for Operation Condition of Ship Oil-Water Separator. Wuhan University of Technology, Wuhan. 